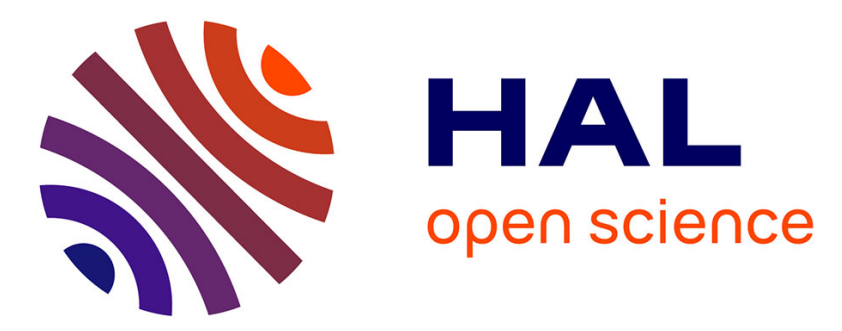

\title{
Pilot-scale experimental study of an innovative low-energy and low-cost cooling system for buildings
}

Guilian Leroux, Nolwenn Le Pierrès, Louis Stephan, Etienne Wurtz, Jocelyn Anger, Laurent Mora

\section{- To cite this version:}

Guilian Leroux, Nolwenn Le Pierrès, Louis Stephan, Etienne Wurtz, Jocelyn Anger, et al.. Pilot-scale experimental study of an innovative low-energy and low-cost cooling system for buildings. Applied Thermal Engineering, 2019, 157, pp.113665 -. 10.1016/j.applthermaleng.2019.04.075 . hal-03485884

\author{
HAL Id: hal-03485884 \\ https://hal.science/hal-03485884
}

Submitted on 20 Dec 2021

HAL is a multi-disciplinary open access archive for the deposit and dissemination of scientific research documents, whether they are published or not. The documents may come from teaching and research institutions in France or abroad, or from public or private research centers.
L'archive ouverte pluridisciplinaire HAL, est destinée au dépôt et à la diffusion de documents scientifiques de niveau recherche, publiés ou non, émanant des établissements d'enseignement et de recherche français ou étrangers, des laboratoires publics ou privés.

\section{(ㅇ)(1) $\$$}

Distributed under a Creative Commons Attribution - NonCommercial| 4.0 International 


\title{
Pilot-scale experimental study of an innovative low-energy and low-cost cooling system for buildings
}

\author{
Guilian Leroux ${ }^{1,2,3}$, Nolwenn Le Pierrès ${ }^{1 *}$, Louis Stephan ${ }^{3}$, Etienne Wurtz $^{3}$, Jocelyn Anger ${ }^{3}$, Laurent Mora ${ }^{2}$ \\ ${ }^{1}$ LOCIE laboratory, Université Savoie Mont Blanc, CNRS UMR5271, Le Bourget du Lac, France \\ ${ }^{2}$ I2M, Université de Bordeaux, Talence, France \\ ${ }^{3}$ SBST, CEA, Le Bourget du lac, France
}

\begin{abstract}
An experimental study of an innovative low-energy and low-cost cooling system for buildings is presented. To achieve low-energy use, this cooling system simultaneously makes use of three available heat sinks: the ground, evaporation of water and radiation to the sky. This simple, inexpensive and energy-saving system was installed on a single-family 100- $\mathrm{m}^{2}$ house in Bordeaux (South-West of France) and tested during summer 2015. On the test sequence presented (10-25 August), this system dissipated an average of 8.5 $\mathrm{kWh}$ /day of heat from the building, with a maximum of $19.3 \mathrm{kWh}$. This energy was dissipated mainly into the ground and crawl space $(4.5 \mathrm{kWh} /$ day) and by evaporation and radiative cooling $(4.7 \mathrm{kWh} / \mathrm{day})$. The system COP over the period was 19 and it maintained an inside air temperature under $27^{\circ} \mathrm{C}$ even during warm summer days, with approximately 42 L/day water consumption.
\end{abstract}

Keywords: Cooling system, Evaporation, Ground cooling, Pilot-scale experiment, Buildings

* Corresponding author:

Tel.\# +(33) 479758858

email address: Nolwenn.Le-Pierres@univ-smb.fr 


\section{Introduction}

With around 16\% of the final world energy use in 2010 (final energy is energy consumed by end users, such as households, industry and agriculture, IEA, 2013) and an average growth rate of $1.6 \%$ per year, the household sector is a major source of greenhouse gas emissions and energy use. This increase is stimulated by wider use of new appliances and rapid market development of air conditioning systems. In addition, a dramatic increase in the cooling needs is predicted (Isaac and Van Vuuren, 2009) in the next decade due to this development of air conditioning use in emerging countries with hot climates and large populations such as India, China and Brazil. For example, Chaturvedi et al. (2014) predicted that the cooling energy use in India would increase by a factor of 29 between 2005 and 2095. Currently, the cooling demand in buildings is essentially met by traditional heat pump systems that involve high electricity use. Moreover, the refrigerant fluid generally used for air conditioning (R410A) contributes substantially to global warming (GWP of 1725 (IPCC, 2001)). To meet these climatic challenges and fulfil the commitments made during the latest climate conferences, it is now urgent to develop innovative low-energy cooling systems.

Various low-energy cooling systems and strategies to alleviate summer discomfort are already available, as reported in Geetha and Velraj (2012), who suggest distributing them into three categories: solar protection, dampening of the temperature peak with massive construction and dissipating energy in heat sinks available around the building. Solar assisted air conditioning technologies as described in Henning (2007) use a solar heat production and are not considered as low-energy cooling systems in this work.

To decrease the cooling demand, solar protection and inertia should be used first. But these solutions could be difficult to control and may not be effective enough to offer appropriate thermal comfort in a building. Consequently, systems to extract and dissipate overheat from the building are needed. In their report on the state of the art on passive cooling dissipation techniques for buildings, Santamouris and Koloktsa (2013) list three main axes.

The first one is based on ventilation. The idea here is either to increase the speed of the air in the building to decrease the sensation of discomfort or to adapt the ventilation rate according to the outside conditions (Artmann and al. 2007).

The second axis uses the coolness of the ground. Indeed, the temperature of the ground at a certain depth remains nearly constant during the year and provides a potential heat sink during the summer. Ground cooling systems have been widely studied (Mihalakakou et al. 1994). In the case of earth-to-air heat exchangers, air is blown through pipes buried in the ground at a certain depth (generally between $0.5 \mathrm{~m}$ and $4 \mathrm{~m}$ ) and exchanges heat with the ground. The air then gets cooler depending the temperature difference between the air and the ground. Such systems can produce substantial difference $(\sim 3-40 \%)$ in the air temperature between the inlet and outlet of the pipe and heating/cooling potential in different climatic 
conditions. The potential of these systems is usually higher for cooling than for heating purposes (Bordoloi et al., 2018; Singh et al., 2018). Air moisture content, outside temperature, pipe depth, pipe radius, pipe length, thermal interference between adjacent tubes, air flow rate, soil characteristics and soil surface treatments, temperature difference between earth and ambient air also have important effect on the performance of such systems, but the impact of tube material on the performance seems negligible. Recently, Khabbaz et al. (2016) conducted an experimental and numerical study of an earth-to-air heat exchanger for air cooling in a residential building in hot semi-arid climate. Simulations proved that the cooling capacity during the hot months (May- September) were between 18 and $20 \mathrm{~W} / \mathrm{m}^{2}$ over the season, with maximum daily capacities of $55-58 \mathrm{~W} / \mathrm{m}^{2}$, depending on the operating parameters. These performances were considered as very promising, especially for small-scale residential buildings. Other results, described in annex 28 of the IEA report $(I E A, 1997)$ for the earth-to-air heat exchanger $(\varnothing=0.2 \mathrm{~m})$, give a potential of 6-30 W/m of pipe depending on the functioning parameters. The cost of such systems is low, as payback period is less than 2 years for the investment and the energy payback time is about 1.3 years (Liu et al., 2019). However, the cost may increase significantly when increasing the burial depth. The material of the pipe can affect the economics of the system significantly. Therefore, the use of a low cost pipe was suggested for these systems (Singh et al., 2018). Another technology is water-based ground heat exchange. It refers to a high-density plastic tube buried underground, through which water, anti-freezing liquid or a mixture of both exchanges heat with the soil. It can be installed horizontally or vertically. In the horizontal type, pipes are buried at depth of 1-2 $\mathrm{m}$ and the cooling potential is $15-30 \mathrm{~W} / \mathrm{m}$ of tube (Aresti et al., 2018). It is a costeffective system and appropriate when there is space available and trenches easy to dig. The efficiency of this technology is greatly affected by the correct sizing of tubes, the tube configuration and the velocity of circulating liquid, tube depth, the grouting material of the heat exchanger, the existence of water flow in the underground layers and the thermal properties of the earth (Stylianou et al. 2017). The application of waterbased ground heat exchangers again can play a significant role in efficient buildings (Gao et al., 2018).

The third axis concerns the endothermic phenomenon of evaporation of water in contact with dry air, called evaporation cooling or adiabatic cooling. Over the last few years, evaporative cooling has received considerable attention and different systems have been developed. Most popular applications consist in cooling the building envelop (with green roofs (He et al. 2016), roof ponds (Spanakia et al. 2011), pipeembedded in wall (Shen and Li. 2016)) or to cool the air ventilation flow. Among them, direct water evaporation in ventilation air flow is the simplest and best-known application. The literature shows the growing interest and high performance of more complex systems using heat exchangers, called indirect evaporation systems (Daou et al. 2006; Duan et al. 2012). For instance, in an experimental study on dewpoint indirect evaporative cooling systems, Bruno (2011) reports a COP from 6 to 20 depending on outside conditions (air temperature and humidity) with a quasi-linear relationship between the COP and the 
difference between air temperature and dew point. Duan (2011) also developed an indirect evaporative cooler with counter-current heat and mass exchanger. He obtained a COP from 3 to 12 and showed that performance depends strongly on the intake air velocity, temperature and humidity. In a general review about alternative cooling technologies, Brown and Domanski (2014) stated that evaporative cooling likely would not be able to compete with vapour-compression technology since it is not viable in all operating conditions, presents large size and weight and high cost. However, porous material can be used as evaporative surface with advantages of durability, price and availability, and porous ceramic can represent a low-cost technology compared to active evaporative cooling, with the advantage of having practically no maintenance (Oropeza-Perez and Ostergaard, 2018). Ibrahim et al (2003), Velasco Gomez et al (2010) and more recently Boukhanouf et al (2017) presented systems with hollow bricks filled with water set in the ventilation airflow. Depending on the air condition, Boukhanouf reports good performances with a maximum cooling capacity of $225 \mathrm{~W} / \mathrm{m}^{2}$ of wet surface area. Ibrahim et al (2003) showed similar performance with maximum cooling of $224 \mathrm{~W} / \mathrm{m}^{2}$ of evaporator surface measured during the tests. Quadratic formulae relating cooling surface power to saturated vapour pressure difference were derived. More recently, another evaporative cooling system using porous ceramic tubes arrangement was evaluated theoretically and experimentally by the same authors in weather conditions of hot and dry climates (Boukhanouf et al 2018). For this porous tube design, tests showed a specific cooling capacity of $140 \mathrm{~W} / \mathrm{m}^{2}$ of wet ceramic surface and an overall COP of 11.4. Velasco Gomez et al (2010) designed a system with hollow brick to act as either direct or indirect evaporative one, depending on the relative humidity of the outdoor and return air streams. They proved that the performance of these systems improves when outdoor air temperature increases, usually related to low values of relative air humidity, due to the evaporative cooling process. These performances allowed to rank low-cost evaporative cooling as the highest potential for energy saving among all the passive cooling methods for Mexico (Oropeza-Perez and Ostergaard, 2018).

Another heat sink ruled out by Santamouris et al. (2013) in their state of the art on passive cooling dissipation techniques for buildings, is radiative cooling, which uses the low temperature of the sky with radiative exchanges, because of its low power density. However, a recent review by Lu et al. (2016) reported that while different experimental studies on radiative cooling systems showed a potential of $40-60 \mathrm{~W} / \mathrm{m}^{2}$, they were highly dependent on cloud coverage and ambient humidity.

All these studies show significant potential and the growing interest in low-energy cooling systems. Space cooling techniques have multiple objectives (Soni et al., 2016) :

- achieve the lowest possible working cost;

- operate under environmentally safe condition;

- be installed at the lowest possible initial cost; 
- enhance interior comfort level and system durability;

- $\quad$ establish ease of service and maintenance.

As a consequence, existing low-energy cooling systems are still not widespread because of their price, installation difficulties and varying performance depending on the ambient conditions. Based on this observation, a new low-energy cooling system for buildings was imagined and patented (Stephan 2012). The main idea is to propose a low-tech system, which means low maintenance, low investment cost, easy to install and high efficiency. The system simultaneously makes use of three different heat sinks (evaporative cooling, radiative cooling and ground cooling) to dissipate excess heat from a building. Existing hybrid cooling systems are rare. A review by Soni et al (2016) found only 3 existing systems coupling ground cooling and evaporative cooling. Thus, the present paper presents an innovative experimental pilot-scale study of this new low-energy and low-cost cooling system, that couples three cooling technologies. Since this system has never been tested before and has no close equivalent, this paper gives interesting results on a promising system.

In the first part, the principle of the system is described. The second part details the experimental setup and in the last part, the main results are reported and analysed.

\section{Innovative evaporative cooling system}

The main components of the system - illustrated in Figure 1 - are a storage tank (1) (situated in the crawl space thus no additional digging work is needed and investment cost is limited), a heat exchanger (which is used as a heating floor during the winter and can be used as a cooling floor during the summer period) (2), a porous tank (set outside the building along a shaded façade), also called an evaporator (3), a water pump (4), an automatic valve (5) and a three-way valve (9).

The system follows a daily cycle. During the daytime, when the house indoor air temperature exceeds the comfort temperature, cool water passes from the storage tank (1) through the cooling floor (2), removes heat from the building and is then stored back in the porous tank (3). When the evaporator is full, the three-way valve sends water back from the cooling floor directly to the storage tank. During the following night, the water in the evaporator (3) is cooled due to evaporation, radiation and convection at the porous tank surfaces. In the morning, as soon as the temperature of the water contained in the porous tank (3) increases, the automatic valve (5) opens and cool water flows from the evaporator into the storage tank (1). This closes the cooling cycle.

The evaporator (3) is a vertical flat tank installed $30 \mathrm{~cm}$ along the northern wall of the dwelling, with four porous surfaces (top, bottom, front and back sides) and closed with liquid-tight plugs (left and right sides). The porous material used is terra cotta because of its very low cost and has adequate properties 
for the evaporation process. The storage tank makes use of ground cooling because it is installed in the crawl space under the house. The storage tank can be a plastic flexible container, making its installation in the crawl space very easy and its price low. This component is used both as storage and as a heat exchanger with the ground.



Figure 1: Working plan of the cooling system integrated into a dwelling

This system simultaneously uses different heat sinks, thus enhancing the overall cooling potential, and in addition takes advantage of the complementarity of the various heat exchanges: the heat dissipation into the ground, which is continuous and slightly dependent on the outside conditions, and heat dissipation by the evaporator, which has a higher potential but is more dependent on the surrounding conditions. The materials and components used for this system are very inexpensive and can be installed quickly on an existing house. The system can also be connected to existing heating facilities such as heating floors and water-to-air heat exchangers.

This system needs to be tested to evaluate its real performance. Therefore, a prototype of this system was built, installed on a real house in Bordeaux, France, and tested during the summer 2015. This paper presents the main results of this innovative experimental study at the pilot scale. 


\section{Experimental set-up}

\subsection{House}

The house used for this experimental study is a one-floor $100-\mathrm{m}^{2}$ house with crawl space and a nonhabitable attic. The dwelling is divided into three $10-\mathrm{m}^{2}$ bedrooms, a $50-\mathrm{m}^{2}$ sitting room/kitchen, a bathroom and a technical room. The height under the ceiling is $2.5 \mathrm{~m}$, which gives an interior space volume of 250 $\mathrm{m}^{3}$. The roof has four sides with a $20^{\circ}$ slope. Windows account for, respectively, $27 \%, 21 \%, 12 \%$ and $2 \%$ of the south, east, west and north building sides. Figure 2 shows the building used for this study.
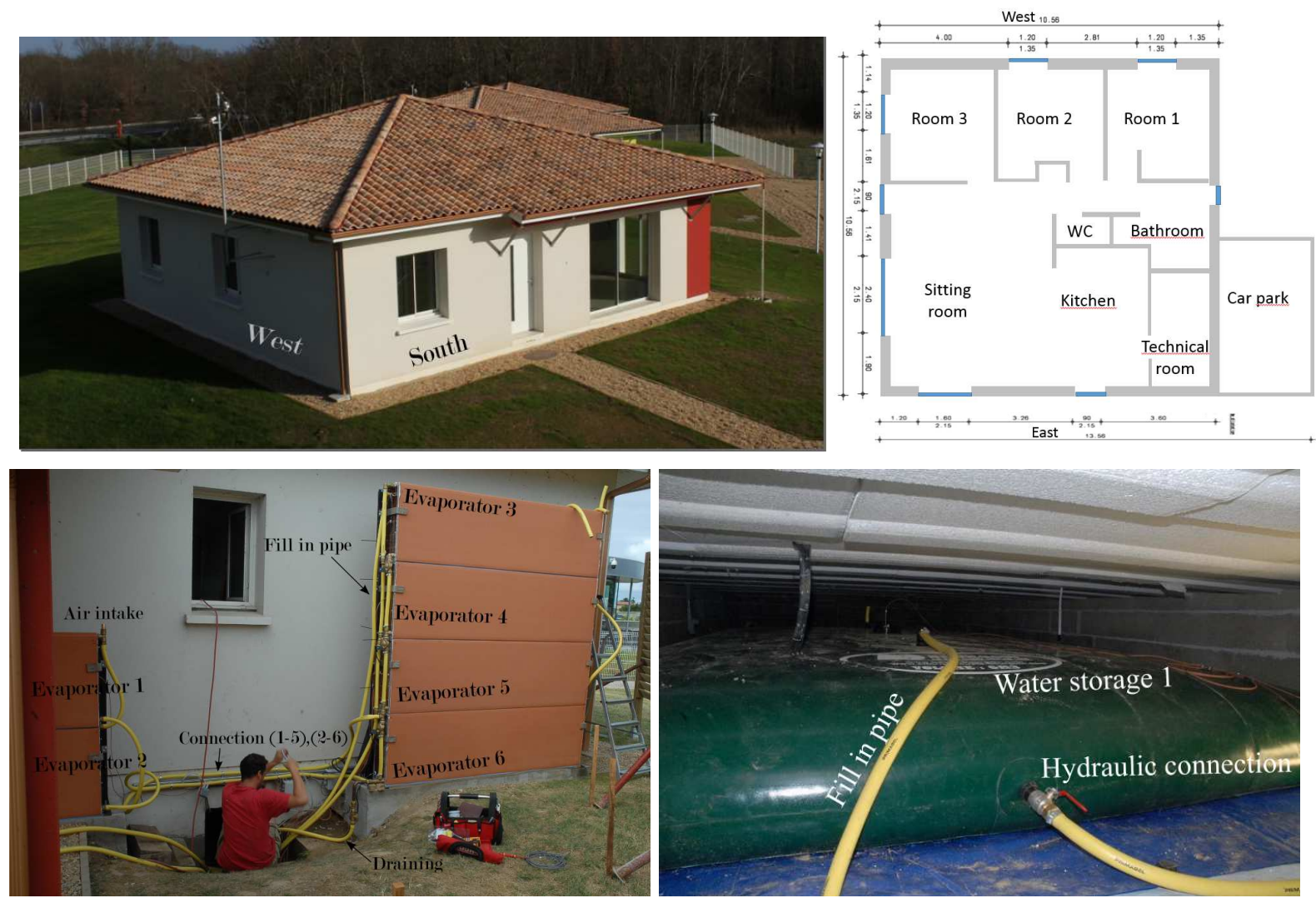

Figure 2: Views of the experimental house, the evaporator and the storage installation

The house is very well insulated with outside walls composed of 20-cm hollow bricks and $10 \mathrm{~cm}$ of glass wool $\left(\mathrm{R}_{\mathrm{th}}=4.25 \mathrm{~m}^{2} . \mathrm{K} . \mathrm{W}^{-1}\right)$; the ceiling is insulated with $30 \mathrm{~cm}$ of blown wool $\left(\mathrm{R}_{\mathrm{th}}=6.85 \mathrm{~m}^{2} . \mathrm{K}^{\mathrm{W}} \mathrm{W}^{-1}\right)$. The cooling floor is composed of a first layer of insulation comprising $13 \mathrm{~cm}$ of polystyrene, a $5-\mathrm{cm}$ concrete slab, another $5-\mathrm{cm}$ polystyrene layer, the pipes (with are $16 \mathrm{~mm}$ diameter and separated by $15 \mathrm{~cm}$ ) and finally $5 \mathrm{~cm}$ of concrete. This cooling floor has little concrete and as a consequence has a low inertia behaviour. Windows are an argon low-emissivity double glazing with conductivity $\mathrm{U}=1.1 \mathrm{~W} \cdot \mathrm{m}^{-2} \cdot \mathrm{K}^{-1}$ and a 
solar factor of 0.58 . An air leak test was conducted and gave an infiltration rate under $4 \mathrm{~Pa}$ of $0.4 \mathrm{~m}^{3} \cdot \mathrm{m}^{-2} \cdot \mathrm{h}^{-}$ 1 .

During the study, the building was unoccupied and internal gains, evaluated at $250 \mathrm{~W}$ in average, were due to an electrical cabinet, a computer and a $200 \mathrm{~L}$ hot water tank on standby position. The ventilation of the building was intentionally stopped, to increase the heat load of the house and thus test the cooling system in more stringent conditions.

\subsection{System components}

The first step of the study sized the different components of the system with a very simple sizing study. A simulation was conducted using the TRNSYS software to estimate the cooling demand of the building during a typical summer in Bordeaux, with shutters closed when the solar irradiation on the windows was above $200 \mathrm{~W} / \mathrm{m}^{2}$, a $0.5-\mathrm{vol} / \mathrm{h}$ ventilation flow rate and a cooling set point at $26^{\circ} \mathrm{C}$. During the simulated summer (1 June to 30 September), $720 \mathrm{kWh}$ of heat must be dissipated, the maximum cooling demand is $2.62 \mathrm{~kW}$ and the mean daily dissipated energy $E_{\mathrm{d}}$ is $6 \mathrm{kWh}$ with a maximum of $\mathrm{E}_{\mathrm{d}, \max }=22 \mathrm{kWh}$.

\subsubsection{Evaporator}

Previous studies (Leroux et al. 2015 and Leroux et al. 2018) evaluated the cooling potential of a terra cotta tank during a night at $50 \mathrm{~W} / \mathrm{m}^{2}$ of tank surface and identified an appropriate material for this application. Details on the porous properties of the chosen terra-cotta are reported in Table 1. The surface area needed to reject $6 \mathrm{kWh}$ from $15 \mathrm{pm}$ to $7 \mathrm{am}$ is $7.5 \mathrm{~m}^{2}$. Considering that water enters the evaporator at $22^{\circ} \mathrm{C}$ and can decrease to $16^{\circ} \mathrm{C}$ at the end of the night, the evaporator volume needs to be $860 \mathrm{~L}$.

Table 1: Properties of the terra-cotta used

\begin{tabular}{|c|c|c|c|c|}
\hline Porosity & Density & Thermal conductivity & Intrinsic permeability & Wall width \\
\hline $0.22 \mathrm{~m}^{3} \cdot \mathrm{m}^{-3}$ & $1970 \mathrm{~kg} \cdot \mathrm{m}^{-3}$ & $2.0 \mathrm{~W} \cdot \mathrm{m}^{-1} \cdot \mathrm{K}^{-1}$ & $7.5310^{-17} \mathrm{~m}^{2}$ & $12 \mathrm{~mm}$ \\
\hline
\end{tabular}

Therefore, the evaporator installed (illustrated in Figure 2) is made with six hollow bricks $61 \mathrm{~cm}$ high, $220 \mathrm{~cm}$ long and $20 \mathrm{~cm}$ deep. Those bricks are manufactured low-cost building bricks. The volume of a brick is $160 \mathrm{~L}$ and weighs $220 \mathrm{~kg}$. The six bricks were installed one on top of the other by stacking them on the edge. The bricks were sanded to remove the thin layer of clay on the outside surface and therefore enhance the evaporation rate. They were set $30 \mathrm{~cm}$ from the northern wall, the total evaporative surface was $16 \mathrm{~m}^{2}$ with $8 \mathrm{~m}^{2}$ exposed to the outside and $8 \mathrm{~m}^{2}$ facing the wall. The total volume was $960 \mathrm{~L}$. 


\subsubsection{Storage}

The storage tank is sized to absorb $\mathrm{E}_{\mathrm{d}, \max }$ with a maximum temperature elevation of $3^{\circ} \mathrm{C}$. This leads to a $6.3-\mathrm{m}^{3}$ storage reservoir. Considering the size of the evaporator and the water losses estimated over the warm season (Leroux et al, 2015), a $9 \mathrm{~m}^{3}$ water storage is actually needed. Given that the system aims to take advantage of the ground cooling, a storage tank shape with a large ground contact area is recommended.

To reach the ideal storage volume with maximum surface and considering the geometry of the crawl space (with separations), the storage tank was split into two cheap flexible plastic reservoirs with a maximum volume of $6 \mathrm{~m}^{3}, 296 \mathrm{~cm}$ wide and $440 \mathrm{~cm}$ long, illustrated in Figure 2. The two storage tanks are hydraulically connected.

\subsubsection{Hydraulic network}

The hydraulic network is made with flexible plastic pipes, $25 \mathrm{~mm}$ in diameter and is represented in Figure 3. It connects the cooling floor, the storage tank and the evaporator. The pump sets a water flow of $1080 \mathrm{~L} / \mathrm{h}$ while the evaporator is filling and $1300 \mathrm{~L} / \mathrm{h}$ when the evaporator is bypassed. A magnetic flowmeter records the mass flow rate in the cooling floor and a counter measures the volume of drained water (see Table 2 and Figure 3). For this experiment, a Sirius master pump was used with a constant speed and $80 \pm 3 \mathrm{~W}$ power consumption.

\subsection{Control}

The system is controlled by an algorithm created with the LabVIEW software. The pump is activated when the maximum indoor air temperature, set to $26^{\circ} \mathrm{C}$, is exceeded and is stopped when the indoor air temperature reaches $25.5^{\circ} \mathrm{C}$. When evaporators are full they are bypassed and the system works with a simple loop between the floor and the storage. Several conditions must be met simultaneously to drain the evaporator: it must not be empty, the temperature of the water in the evaporators must be colder than the water in the storage tank and the temperature of the water in the evaporator begins to increase (morning). For the duration of the test detailed in this article, the system operated without interventions, the building ventilation was cut, as said previously, the south shutters were open and the east and west shutters were closed.

\subsection{Instrumentation}

The instrumentation used for this experiment is illustrated in Figure 3 and detailed in Table 2. The acquisition time step was 3 min. 


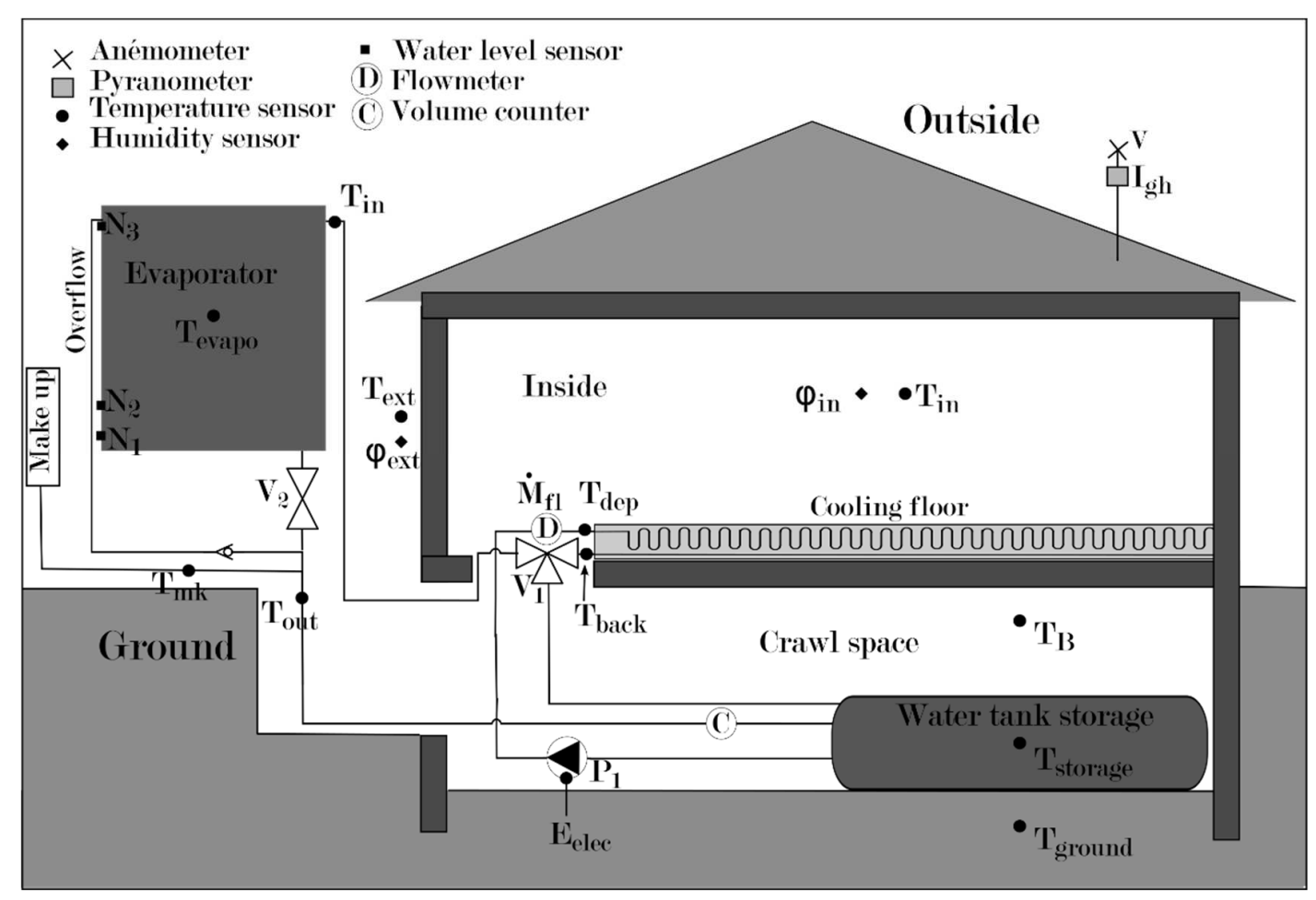

Figure 3: Schematic view of the system installed on the house with the main instrumentation

Table 2: Measurement points

\begin{tabular}{|c|c|c|c|c|c|}
\hline Name & Unit & Type & Range & Accuracy & Description \\
\hline $\mathrm{T}_{\text {in }}$ & ${ }^{\circ} \mathrm{C}$ & TC type $\mathrm{T}$ & -185 to $300^{\circ} \mathrm{C}$ & $\pm 0.5^{\circ} \mathrm{C}$ & Evaporator inlet temperature \\
\hline Tout $_{\text {out }}$ & ${ }^{\circ} \mathrm{C}$ & TC type T & -185 to $300^{\circ} \mathrm{C}$ & $\pm 0.5^{\circ} \mathrm{C}$ & Evaporator outlet temperature \\
\hline $\mathrm{T}_{\mathrm{dep}}$ & ${ }^{\circ} \mathrm{C}$ & TC type $\mathrm{T}$ & -185 to $300^{\circ} \mathrm{C}$ & $\pm 0.5^{\circ} \mathrm{C}$ & Floor inlet temperature \\
\hline $\mathrm{T}_{\text {back }}$ & ${ }^{\circ} \mathrm{C}$ & TC type T & -185 to $300^{\circ} \mathrm{C}$ & $\pm 0.5^{\circ} \mathrm{C}$ & Floor outlet temperature \\
\hline $\mathrm{T}_{\text {storage }}$ & ${ }^{\circ} \mathrm{C}$ & TC type T & -185 to $300^{\circ} \mathrm{C}$ & $\pm 0.5^{\circ} \mathrm{C}$ & Mean temperature center 2 storages \\
\hline $\mathrm{T}_{\mathrm{b}}$ & ${ }^{\circ} \mathrm{C}$ & TC type T & -185 to $300^{\circ} \mathrm{C}$ & $\pm 0.5^{\circ} \mathrm{C}$ & Air crawl space temperature \\
\hline $\mathrm{T}_{\text {ground }}$ & ${ }^{\circ} \mathrm{C}$ & TC type T & -185 to $300^{\circ} \mathrm{C}$ & $\pm 0.5^{\circ} \mathrm{C}$ & Ground temperature $(-0.25 \mathrm{~m})$ \\
\hline $\mathrm{T}_{\text {int }}$ & ${ }^{\circ} \mathrm{C}$ & HD4817T (Deltaohm) & -20 to $80^{\circ} \mathrm{C}$ & $\pm 0.5^{\circ} \mathrm{C}$ & Inside air temperature $(1.1 \mathrm{~m})$ \\
\hline $\mathrm{T}_{\mathrm{ext}}$ & ${ }^{\circ} \mathrm{C}$ & HD4817T (Deltaohm) & -20 to $80^{\circ} \mathrm{C}$ & $\pm 0.5^{\circ} \mathrm{C}$ & Outside air temperature \\
\hline $\mathrm{T}_{\text {evapo }}$ & ${ }^{\circ} \mathrm{C}$ & TC type T & -185 to $300^{\circ} \mathrm{C}$ & $\pm 0.5^{\circ} \mathrm{C}$ & Mean temperature center 6 evapo \\
\hline$\varphi_{\text {ext }}$ & $\%$ & HD4817T (Deltaohm) & $0-100 \%$ RH & $\pm 2.5 \% \mathrm{RH}$ & Outside relative humidity \\
\hline$\varphi$ int & $\%$ & HD4817T (Deltaohm) & $0-100 \%$ RH & $\pm 2.5 \% \mathrm{RH}$ & Inside relative humidity \\
\hline$\dot{\mathrm{M}}_{\mathrm{fl}}$ & $\mathrm{L} / \mathrm{h}$ & MAG1100 Danfoss & $0-30 \mathrm{~L} / \mathrm{s}$ & $\pm 0.5 \%$ & Water flow through the cooling floor \\
\hline $\mathrm{C}$ & $\mathrm{L}$ & Counter & $10-3200 \mathrm{~L} / \mathrm{h}$ & $\pm 1 \mathrm{l} / \mathrm{h}$ & Volume of water drained from evaporator \\
\hline Igh & $\mathrm{W} / \mathrm{m}^{2}$ & CR100 & $1-1300 \mathrm{~W} / \mathrm{m}^{2}$ & $\pm 5.0 \%$ & Global horizontal radiation \\
\hline $\mathrm{v}$ & $\mathrm{m} / \mathrm{s}$ & Cup anemometer & $0-35 \mathrm{~m} / \mathrm{s}$ & $\pm 3.0 \%$ & Air speed \\
\hline Eelec & Wh & Electricity meter & $0-2300 \mathrm{~W}$ & $\pm 0.5 \%$ & Electric consumption of pump P1 \\
\hline
\end{tabular}




\subsection{System cost}

The design of this system intended to develop a low-tech, low cost system. Considering the prototype developed, the overall cost of the system material was below $1000 €$, which is lower than the cost of a conventional air conditioning system for this house. In this cost, the cooling floor cost was not taken into account, as the system takes advantage of the existing heating floor (that is used as cooling floor during the summer season here). In addition, the instrumentation cost that was developed for the detailed study of the prototype behaviour and would not be necessary in a real installation was also excluded.

\section{Main results}

\subsection{Temperature changes in the main components}

The experiment was conducted during August and September 2015. During this period the system worked automatically. A fortnight in August is detailed in this paper and the overall results for the whole period are reported in Table 3 and discussed at the end of the section.

First, Figure 4 shows the temperature of the main components of the system from 10 to 25 August 2015: the temperature of the water in the storage tank $\left(\mathrm{T}_{\text {storage }}\right)$, the air in the living room $\left(\mathrm{T}_{\text {int }}\right)$, outdoor air $\left(\mathrm{T}_{\mathrm{ext}}\right)$ and the temperature in the evaporator, which represents air or water temperature depending on the filling of the evaporator $\left(\mathrm{T}_{\text {evapo }}\right)$.

Every night the temperature of the water contained in the evaporator decreased from 0 to $2^{\circ} \mathrm{C}$ below the minimum outside air temperature of the night. Throughout this 2-week period, air temperature in the living room $\left(\mathrm{T}_{\text {int }}\right)$ remained below $27^{\circ} \mathrm{C}$. Moreover, the house temperature decreased slowly during the night (no ventilation and weak air infiltration) and increased quickly during the day due to solar gains from the south façade. Building energy management was not optimized in this case but was chosen to test the system in high cooling demand periods. Furthermore, water temperature in the storage tank changed between $19^{\circ} \mathrm{C}$ and $22^{\circ} \mathrm{C}$. The rising steps are characteristic of the cooling periods in the house, the falling steps of drains and the slowly decreasing slopes when the system was not used is due to the exchanges with the ground and the crawl space. It is interesting to note that after an initial warm period (11-13 August), during which the storage capacity was heavily used, the storage temperature increased from $20^{\circ} \mathrm{C}$ to $22^{\circ} \mathrm{C}$. The following 4 colder days were sufficient to return its temperature to $19^{\circ} \mathrm{C}$. 


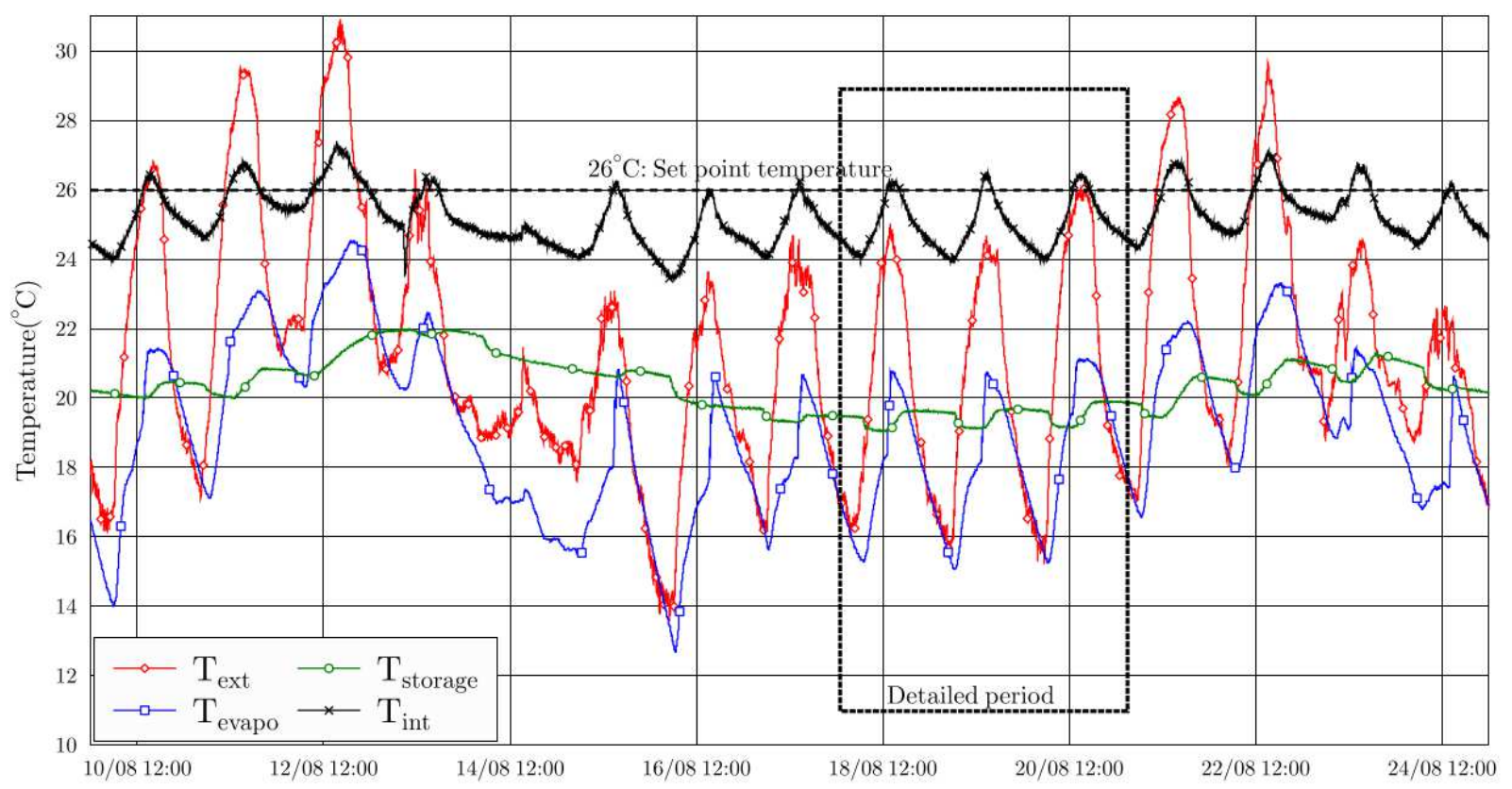

Figure 4: Temperature of the main components of the cooling system from 10 to 25 August 2015

\subsection{Dynamics of the system during a detailed period}

Figure 5 shows the dynamics of the system over 3 days (18-20 August 2015). The different operating phases are represented by a colour code.

When the internal temperature exceeded the set-point temperature $\left(26^{\circ} \mathrm{C}\right.$, dotted line $)$, the house was cooled by a cool water flow in the cooling floor (hatched zone). The low inertia of the floor means that the system had a rapid influence on the interior temperature. First, the water leaving the cooling floor filled the evaporator (dark blue zones), characterized by a sharp increase in the evaporator temperature. When the evaporator was full, water from the cooling floor went directly back into the storage tank: an increase of the storage temperature can be observed at these moments. The water stored in the evaporator cooled down (light blue zones) with the radiation and evaporation effects, and was emptied (purple zones) when the minimum temperature was reached (in the morning). The impact of the draining of the evaporator can be observed with the sharp decrease in the storage temperature. 


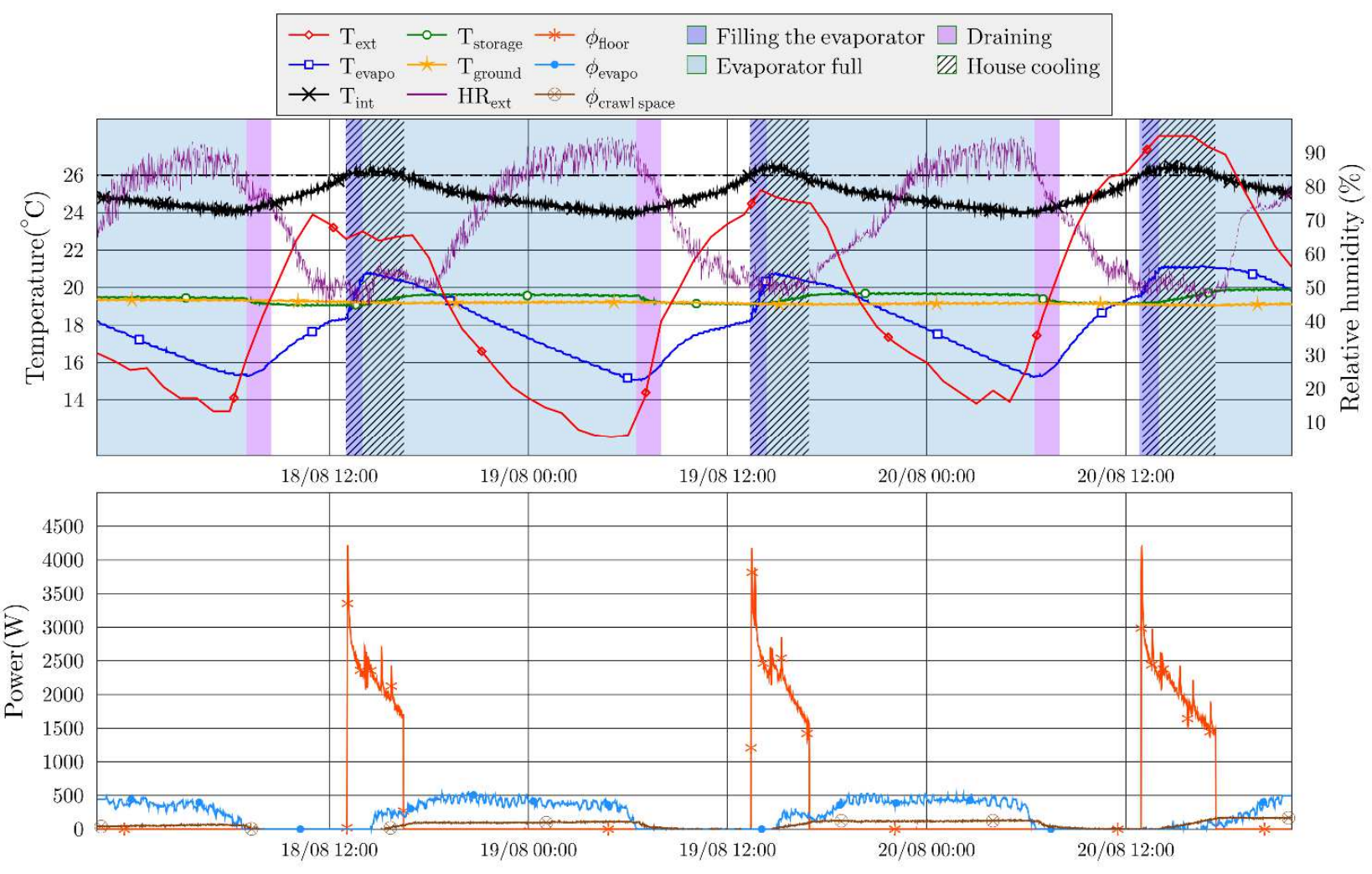

Figure 5: Behaviour of the cooling system, with temperatures and heat exchanged for the main components over 3 days (18-20 August 2015)

\subsection{Heat exchanges}

The thermal power exchanged by the cooling floor $\phi_{f l}$, the evaporator $\phi_{\text {evapo }}$ and the storage in the crawl space $\phi_{b}$ were calculated and are represented in Figure 5. Their expressions are detailed and the results analyzed in the following.

$$
\phi_{f l}=\dot{M}_{f l} C p_{w}\left(T_{b a c k}-T_{d e p}\right)
$$

The heat extracted from the house by the floor corresponds to the enthalpy variation of the water between the inlet of the cooling floor and its outlet. The heat extracted from the house when the cooling was activated (orange) varied from 4000 to $1500 \mathrm{~W}$. It can be seen that $\phi_{f l}$ decreased during the day, due both to the cooling of the inertia mass of the concrete of the floor around the pipes during the cooling phase and the fact that the water temperature in the storage and therefore at the cooling floor inlet increased during the day. 
The heat dissipated by the evaporator is more difficult to evaluate since there is both heat and mass transfer. As stated in the introduction, the performance of evaporative cooling as well as radiative cooling strongly depend on ambient conditions, air velocity over the evaporator wall, surrounding surfaces, as well as air temperature and humidity. In this analysis, the calculation was done only for the cooling period (i.e. when the evaporator is full). $\phi_{\text {evapo }}$ reported in Figure 5 represents useful cooling, which corresponds to the heat exchanged between the outside and the mass of water present in the evaporator at the end of the cooling processes, that can be used to cool the building. This is a global formulation taking into account the evaporation, convection and radiation processes occurring at the external surface of the porous tank. It can be expressed by the following formulation:

$$
\phi_{\text {evapo }}=m_{w} C p_{w} \frac{d T_{\text {evapo }}}{d t}
$$

Figure 5 shows that on the 3 days presented, just after the filling, the cooling power of the water was low, then it increased and became nearly constant around $500 \mathrm{~W}$. This is because at the filling time, outside temperature was higher than water temperature in the evaporator, and convection between the evaporator and the ambient air slowed down the cooling of the water despite the evaporation phenomenon. On this 3day sequence, the average cooling power (including convection, evaporation and radiation) was $72 \mathrm{~W} / \mathrm{m}^{2}$ considering only the northern surface of the porous tank exposed to the surroundings and $31 \mathrm{~W} / \mathrm{m}^{2}$ considering the entire evaporator surface (including the surface facing the house). During these 3 days, the water temperature in the porous reservoir was almost always below the external air temperature, i.e. convection, even during the night, tended to slow down the cooling process.

The heat exchanged in the crawl space was calculated considering the conductive exchanges with the ground at the bottom of the storage tank and the radiative and convective exchanges of the upper part. Thus the power exchanged by the storage with the air and the walls and ceilings of the crawl space and with the ground can be written as:

$$
\phi_{b}=G_{1}\left(T_{\text {storage }}-T_{b}\right)+G_{2}\left(T_{\text {storage }}-T_{\text {ground }}\right)
$$

The experimental coefficients $G_{1}$ and $G_{2}$ were calibrated on a previous test sequence to $G_{1}=217 \mathrm{~W} / \mathrm{K}$ and $G_{2}=104 \mathrm{~W} / \mathrm{K}$. The calibration was done in July with the same installation. The cooling power exchanged by the system in the crawl space is relatively small on the sequence detailed (around $60 \mathrm{~W}$ ), but these exchanges are permanent and, overall, contribute significantly to the total cooling effect over several days. The impact of the heat exchanged by the storage increased during hot periods. In this case, the water temperature in the storage tank sharply increased and created significant deviations with the relatively stable ground temperature. 


\subsection{Daily balances}

The exchanges described in the previous section are integrated daily and presented in Figure 6 (1025 August 2015). The relative humidity indicated represents the average daily value of the outside air when the evaporator is full (as presented in Figure 5). There is significant uncertainty around the power exchanged, since the intrinsic uncertainty of the thermocouples is not negligible in comparison with the temperature differences used in these calculations. This uncertainty is also presented in Figure 6. During this fortnight, the system dissipated an average of $8.5 \mathrm{kWh} /$ day of heat from the building, with a maximum of $19.3 \mathrm{kWh}$ on 12 August. This energy was dissipated into the ground and the air in the crawl space (mean: $4.5 \mathrm{kWh} /$ day) and by the evaporator (mean: $4.7 \mathrm{kWh} /$ day). During the first 3 hot days (11-13/08), the energy extracted from the house was high $(43 \mathrm{kWh})$. The temperature of the outside air as well as the ambient relative humidity (71.8-81.2\%) were high during the night, leading to low energy dissipated by the evaporator ( $8.4 \mathrm{kWh}, 11-13$ August). The temperature of the water in the storage tank increased during this period from 20 to $22^{\circ} \mathrm{C}$ due to the imbalance between the incoming and dissipated energy in the storage tank. The temperature of the ground ( $25 \mathrm{~cm}$ under the storage tank) and the water temperature in the storage tank are also presented in Figure 6. The heat dissipated in the crawl space increased as the temperature differences between the ground and the storage tank increased. Therefore, exchanges between the storage and the crawl space increased progressively with a total of $23 \mathrm{kWh}$ dissipated during these 3 days, maintaining the cooling potential of the system.

From 14 to 17 August, the outside temperature was moderate, with cool nights. On 14 August, no cooling needs were observed in the house, thus water was not flown to the cooling floor and thus to the evaporator. The heat extracted from the building during the three following days (15-17 August) was low (12.1 kWh over the 3 days), while the cooling process in the evaporator was efficient ( $21 \mathrm{kWh})$. The temperature of the water in the storage tank quickly decreased during this time.

Another warm period is visible from 20 to 23 August, for which the same mechanism as during the 3 first days (10-13 August) was repeated.

Overall, for this experiment, it can be seen that during hot periods, the evaporator efficiency was low, as shown in Figure 7a, but exchanges in the crawl space were then high, as they are function of the temperature difference between the storage tank and the ground and the crawl space air (Figure 7b) and maintained a sufficiently low water temperature in the storage tank (Figure 6). Then, during cooler days, the evaporator was more efficient, allowing the water temperature to drop quickly. These two cooling modes were therefore complementary in this system. However, the link between the relative humidity outside during the evaporation phase and the evaporator efficiency is not clear, as shown in Figure 7c or 7d following Bruno's approach (2011). Indeed, the evaporator behaviour depends both on radiation, evaporation and convection 
phenomena, and the relative share of each phenomenon depends also on other parameters, such as the equivalent sky temperature or the wind speed, as shown in Leroux et al. (2018). Moreover, the measurements were taken for a too short period to reveal possible limitations of heat transfer to the ground. Indeed, the ground may progressively absorb heat from the tank and its temperature could increase over the summer months as well as over the years. This ground behaviour depends strongly on the composition of the soil and the presence of underground water and is beyond the purpose of this study, but it has to be highlighted that measurements conducted here were so short term that they merely reflect the initial condition of the soil under the tank, and this aspect would have to be closely studied in the following years.

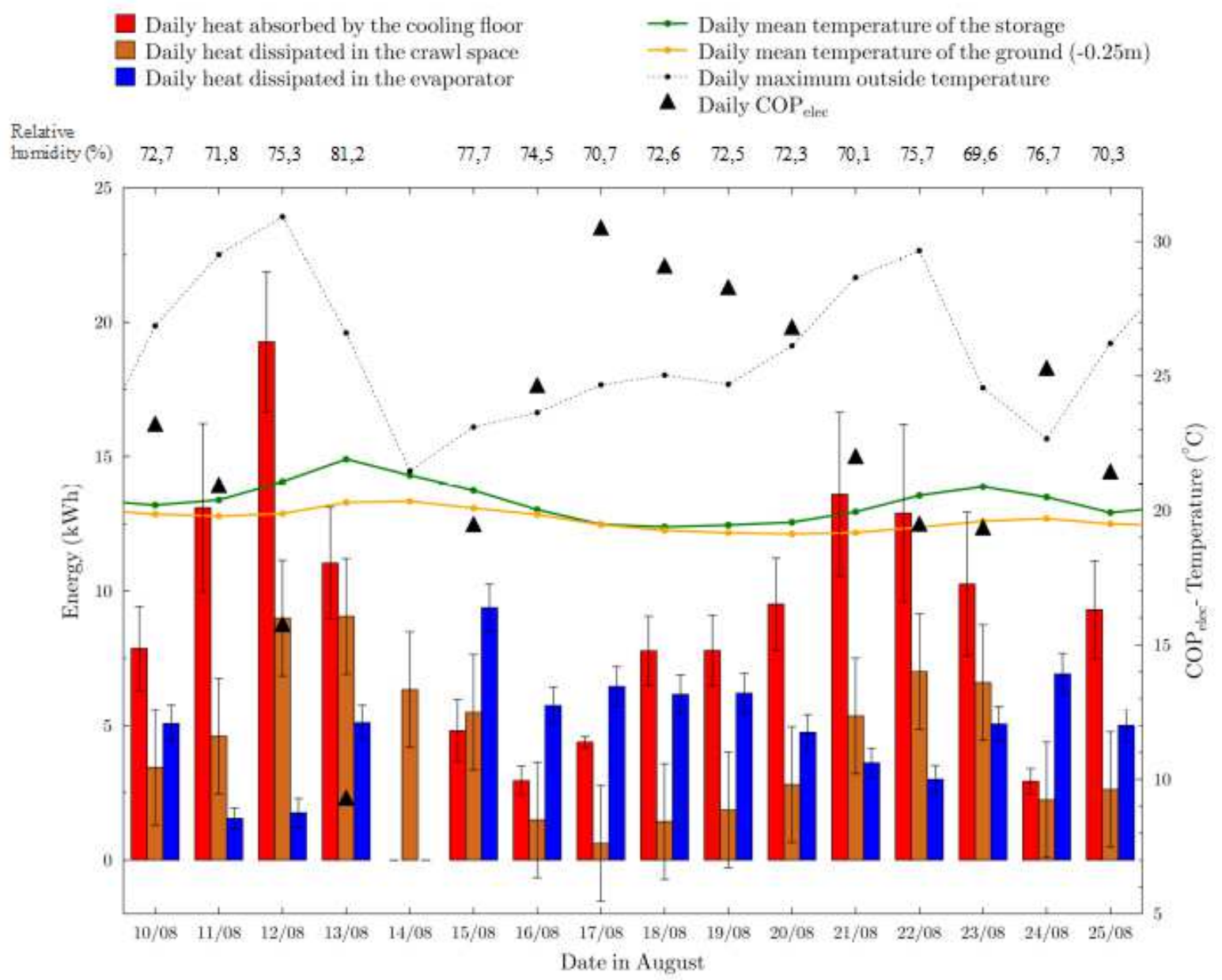

Figure 6: Daily heat exchanged by the main components of the cooling system (evaporator, tank and cooling floor). The relative humidity indicated represents the average daily value when the evaporator is full (as presented in Figure 5). 

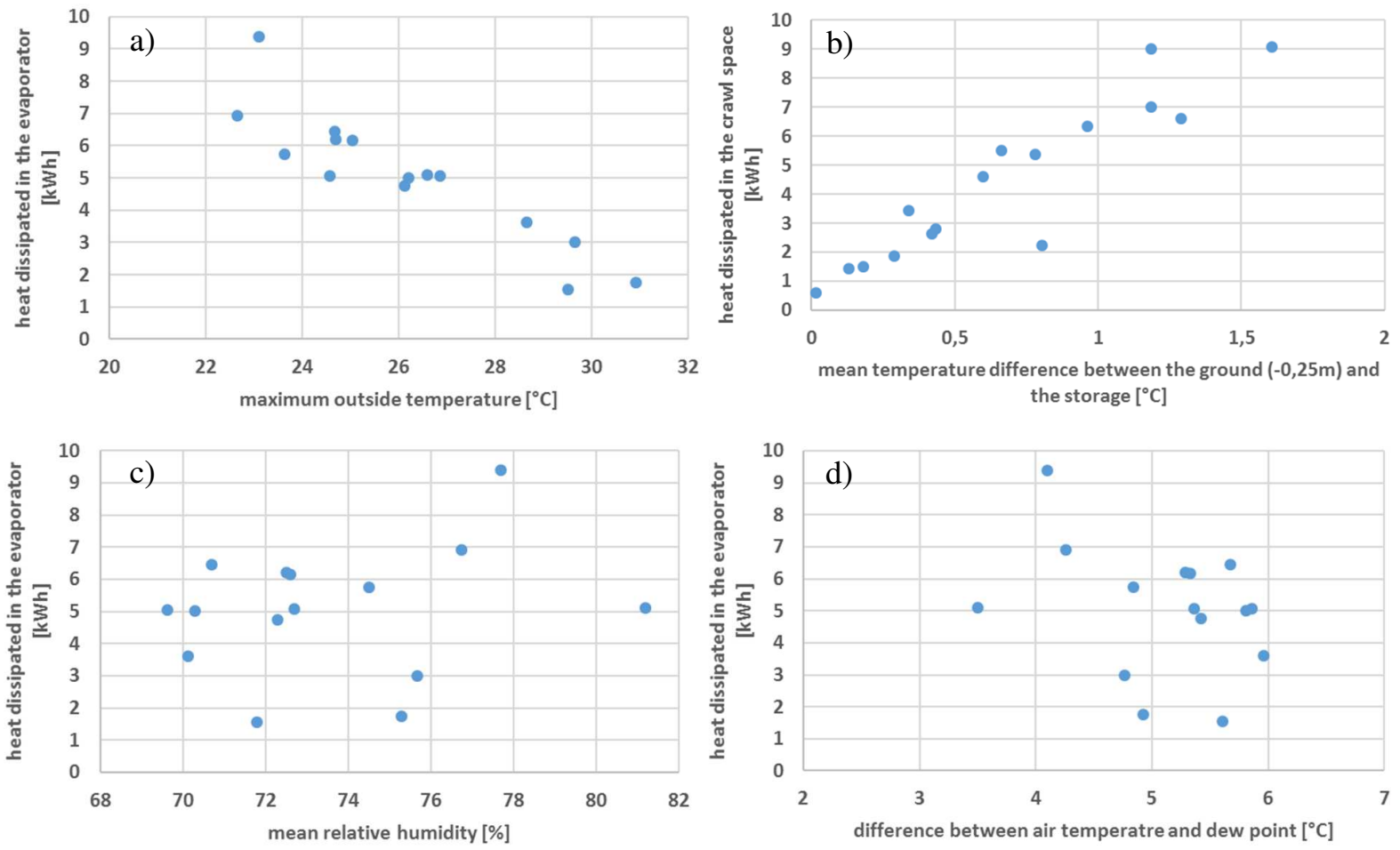

Figure 7: Impact of the ambient conditions on the heat exchanged during the 10-25 August period. Influence of a) outside temperature, b) ground and storage tank temperature, c) ambient relative humidity, d) air temperature and dew point

\subsection{Coefficient of Performance}

The system's electrical coefficient of performance $C O P_{\text {elec }}$ is considered as the ratio of the excess heat extracted from the dwelling by the system $\mathrm{E}_{\mathrm{fl}}$ to the electrical energy supplied to operate the system. The system's power consumption stems mainly from the pump.

$$
C O P_{\text {elec }}=\frac{\int \phi_{f l} d t}{E_{\text {elec }}}=\frac{E_{f l}}{E_{\text {elec }}}
$$

The daily $\mathrm{COP}_{\text {elec }}$ of the system is reported in Figure 6. The daily $\mathrm{COP}_{\text {elec }}$ is very high (between 9 and 30), because the power consumption of the system is very low. We can also observe a large variation of the $\mathrm{COP}_{\text {elec }}$ over several days, from 9.2 on the $13^{\text {th }}$ to 30.5 on the $17^{\text {th }}$. The lower COPs are reached when the storage temperature is the highest. The average COP over the entire period is 19.1.

\subsection{Water consumption}

The system's water consumption is difficult to measure on this prototype due to the reactivity of the three-way valve allowing the evaporator to be bypassed. Therefore, the amount of water used to fill the 
evaporator was not measured. To estimate the system's water consumption, one can consider the consumption of water measured in the laboratory and reported in Leroux et al. (2015), which gives an average evaporation rate of $1.8 \mathrm{~g} \cdot \mathrm{min}^{-1} \cdot \mathrm{m}^{-2}$ for a summer day in Bordeaux. Thus, with the evaporator surface installed in this prototype, the water consumption would be around $42 \mathrm{~L}^{\mathrm{day}}{ }^{-1}$.

\subsection{Overall experimental results}

Table 3 is used to aggregate performance indicators. The discomfort level is calculated as the product of:

- the time (in hour) with house temperature $\mathrm{T}_{\text {int }}$ over the target temperature $\mathrm{T}_{\text {tar }}\left(27\right.$ or $26^{\circ} \mathrm{C}$ here)

- $\quad$ and the temperature difference between the house temperature and the target temperature:

$$
\text { Dis }=\sum_{\text {period }}\left[\Delta t_{T_{\text {int }}>T_{\text {tar }}} \cdot\left(T_{\text {int }}-T_{\text {tar }}\right)\right] \quad \text { (with } \mathrm{t} \text { in hour) }
$$

Table 3: Main results of the experiment

\begin{tabular}{|l|c|c|c|}
\hline \multirow{2}{*}{ Days } & & $\begin{array}{c}\text { August } \\
\text { fortnight }\end{array}$ & Whole period \\
\hline \multirow{2}{*}{ Excess heat extracted from the building } & $\mathrm{kWh}$ & 136.7 & 298 \\
\cline { 2 - 4 } & $\mathrm{kWh} / \mathrm{day}$ & 8.5 & 8.3 \\
\hline \multirow{2}{*}{ Heat dissipated by the evaporator } & $\mathrm{kWh}$ & 75.5 & 230 \\
\cline { 2 - 4 } & $\mathrm{kWh} / \mathrm{day}$ & 4.7 & 6.4 \\
\hline \multirow{2}{*}{ Heat dissipated in the crawl space } & $\mathrm{kWh}$ & 71.8 & 137 \\
\cline { 2 - 4 } & $\mathrm{kWh} / \mathrm{day}$ & 4.5 & 3.8 \\
\hline Electrical consumption & $\mathrm{kWh}$ & 7.1 & 13 \\
\hline Mean storage temperature & ${ }^{\circ} \mathrm{C}$ & 20.8 & 19.9 \\
\hline System COP & - & 19.1 & 20.8 \\
\hline Discomfort hours $>26^{\circ} \mathrm{C}$ & ${ }^{\circ} \mathrm{C} . \mathrm{h}$ & 64 & 120 \\
\hline Discomfort hours $>27^{\circ} \mathrm{C}$ & ${ }^{\circ} \mathrm{C} . \mathrm{h}$ & 4 & 7 \\
\hline
\end{tabular}

The results from the detailed test period (10-25 August) are similar as the results for the whole test period (including both August and September 2015). The table shows that for 36 days of use, with a very high COP above 20 , the heat extracted from the house was on average $8.3 \mathrm{kWh} /$ day. The number of hours of discomfort observed in the dwelling is very moderate, with only $7 \mathrm{~h}$ measured above $27^{\circ} \mathrm{C}$ during the period. The main difference between this long period and the August fortnight is the repartition of the heat sinks: the heat rejected from the evaporator was $6.4 \mathrm{kWh} /$ day, compared to $3.8 \mathrm{kWh} /$ day rejected in the crawl space over 
the whole period. This is due to the fact that the average temperature of the storage was quite low in September, as the outside temperature was also moderate, thus heat transfer to the ground decreased, but heat transfer from the evaporator was enhanced. During a few days in September, a temperature of the storage higher than the ground temperature was even observed, as the evaporation process was able to decrease strongly the storage temperature during these days and in this situation, the storage cooled down the ground below the storage tank.

It must be emphasized that during the test period, weather conditions were quite mild. Thus, this system was tested under favourable conditions for convective heat transfer around the evaporator. The building cooling needs still existed as solar gains were high, but in a real inhabited household, opening of the windows of the house would have significantly decreased its cooling loads.

\section{System performances and integration discussion}

The evaporator power was active only during a period of the day, whereas the heat exchanged with both air and the ground in the crawl space was continuous. The specific heat dissipated from the storage reservoir in August was of $2.3 \mathrm{~W} / \mathrm{m}^{2}$ in average. This is low compared to the values found in the literature (an average of $50 \mathrm{~W} / \mathrm{m}^{2}$ for experimental ground-to-air heat exchangers can be calculated from studies reviewed by Bordoloi et al., 2018, which, in turn, is lower than the average ground-to-water systems potential (Aresti et al., 2018)). This low value is logical, as the ground-to-water and air-to-water exchanges in the crawl space here can be qualified as 'passive' ones, with only very low water velocity in the reservoir and only natural convection of the air in the crawl space. Moreover, a numerical study (Leroux, 2016) performed using the model presented in (Leroux et al., 2018) showed that the seasonal performance of the system increased as the storage reservoir volume and external exchange area increased. This component is thus crucial for the efficiency of the system.

The heat exchanged from the evaporator in August amounted to $31 \mathrm{~W} / \mathrm{m}^{2}$ in average which is similar to the values found in the literature (radiative cooling systems show a potential of 40-60 W/m² according to $L u$ et al. (2016)). The numerical study showed that, logically, for a given volume of evaporator, it is advisable to have the greatest possible evaporating surface. But it also showed that the evaporator volume should be significantly lower than the storage one, to keep the best possible system performance: this proves the interest of the coupling of both components for this system.

This study is only a first step toward a comprehensive study of this innovative system. These experimental results show that the system can provide efficient cooling of a building in the climatic conditions of Bordeaux, which present quite warm summer days but also milder summer nights and colder and longer winters that could allow cooling the ground and the crawl space air between two hot periods. In Bordeaux 
summer conditions, the air humidity is generally sufficiently low to allow evaporative cooling of the evaporator at the end of afternoons, followed by efficient convective cooling during nights, when the ambient air temperature has sufficiently decreased. These phenomena would be different in humid climates, where evaporative cooling would not be possible and radiative cooling less efficient.

In the tests presented, the system had just been installed in the building, so the ground temperature and the crawl space air had not been disturbed by any heat source previously. This could be modified over long time periods, as the heat dissipated by the water tank could progressively heat up the surroundings.

Another important aspect that was highlighted in the introduction as well as in previous studies (Leroux et al, 2018) is the air velocity at the evaporator surface: in case of still air, both evaporative and convective phenomena are penalised.

All these climatic and surroundings conditions have to be taken into account when evaluating the performance of this system, and a modelling of the behaviour of the overall system, taking into account all these phenomena, should be performed before implementation.

\section{Conclusion and outlooks}

This study gives the main results of an experimental investigation conducted to test the performance of an innovative cooling system. The experiment was conducted at the pilot scale on a house. The system was installed and tested during summer 2015 in Bordeaux (France). During the detailed period of 10-25 August, the system operated autonomously. The results demonstrated that this low-cost system has good potential since it evacuated about $137 \mathrm{kWh}$ of excess heat from the house and maintained a very good level of thermal comfort in the building. Under the conditions of the experiment, the system's very low power consumption provides a very high coefficient of performance of 19.1. For the whole test period (August and September 2015), the COP was even higher (20.8).

The complementarity between the different heat sinks makes it possible to maintain good performance throughout the summer. The system is very cheap, simple and robust, as expected, and should be a pertinent alternative to electrical compression cooler technology in terms of performance. However, this system cannot be an option in regions where water scarcity is an issue, its evaporation performances would be strongly reduced in humid climates and it requires a basement or a crawl place, not available on all buildings. Other studies on the ageing of the system must be undertaken to provide greater reliability. Indeed, possible limitation of the heat transfer to the ground could appear after long heating periods, as the ground temperature would be affected by this heat load. Moreover, the material characteristics of the evaporator wall and the coupled convection, radiation and evaporation phenomena could be affected by limestone 
deposit or algae growth over, respectively, the evaporator external and internal surfaces. Finally, the technical problems that could happen during winter, when sub-zero temperatures occur for example, are still to be experimentally evaluated. From a modelling point of view, this system should also be studied to optimize its overall performance as a function of climatic and surroundings conditions as well as energy and power demand, and compared with other low-energy systems.

\section{Nomenclature}

Latin letters

C- Counter

$\mathrm{Cp}$ - Specific heat capacity $\left(\mathrm{J} \cdot \mathrm{kg}^{-1} \cdot \mathrm{K}^{-1}\right)$

Dis - discomfort level (K.h)

E - Energy (J)

$\dot{\mathrm{M}}$ - Water mass flow rate $\left(\mathrm{kg} \cdot \mathrm{s}^{-1}\right)$

$\mathrm{m}$ - Mass (kg)

$\mathrm{G}$ - Global conductance (W.K ${ }^{-1}$ )

I - Irradiation (W.m-2)

$\mathrm{R}$-Thermal resistance $\left(\mathrm{m}^{2} . \mathrm{K} . \mathrm{W}^{-1}\right)$

$\mathrm{RH}$ - relative humidity

$\mathrm{t}$ - Time (s)

$\mathrm{T}$ - Temperature (K)

$\mathrm{v}$ - Wind velocity $(\mathrm{m} / \mathrm{s})$

$\mathrm{U}$ - Window conductivity $\left(\mathrm{W} \cdot \mathrm{m}^{-2} \cdot \mathrm{K}^{-1}\right)$

Greek letters

$\varphi$ - Relative humidity

$\phi$ - Heat flux (W)

\section{Subscripts}

b - crawl space

back - from the cooling floor

d - daily

dep - departure of cooling floor

elec - electric

evapo - evaporator

ext - outside

$\mathrm{fl}$ - floor

gh - global horizontal

in - inlet evaporator

int - inside the building

max - maximum

out - outlet evaporator

tar - target

th - thermal

w - water 


\section{Acknowledgements}

Funding for this project was provided by a grant from la Région Rhône-Alpes with the explora-doc program and by the Assemblée des Pays de Savoie.

\section{References}

Aresti L., Christodoulides P., Florides G. 2018. A review of the design aspects of ground heat exchangers. Renewable and Sustainable Energy Reviews 92: 757-773

Artmann N. Manz H. Heiselberg P. 2007. Climatic potential for passive cooling of buildings by night-time ventilation in Europe. Applied Energy 84(2): 187-201

Bordoloi N., Sharma A., Nautiyal H., Goel V. 2018. An intense review on the latest advancements of Earth Air Heat Exchangers, Renewable and Sustainable Energy Reviews 89: 261-280

Boukhanouf R., Alharbi A., Ibrahim H.G., Amer O., Worall M. 2017. Computer modelling and experimental investigation of building integrated sub-wet bulb temperature evaporative cooling system. Applied Thermal Engineering 115: 201-211

Boukhanouf R., Amera O., Ibrahim H., Calautit J. 2018. Design and performance analysis of a regenerative evaporative cooler for cooling of buildings in arid climates. Building and Environment 142: 1-10

Brown J.S., Domanski P.A. 2014. Review of alternative cooling technologies, Applied Thermal Engineering 64 (1-2) :252-262

Bruno, F. 2011. On-site experimental testing of a novel dew point evaporative cooler. Energy and Buildings 43: $3475-3483$

Chaturvedi V., Eom J., Clarke L.E., Shukla P.R. 2014. Long term building energy demand for India: Disaggregating end use energy services in an integrated assessment modelling framework. Energy Policy 64: 226-242

Daou K., Wang R.Z., Xia Z.Z. 2006. Desiccant cooling air conditioning: a review. Renewable and Sustainable Energy Reviews 10: 55-77

Duan Z., Zhan C., Zhang X. Mustafa M., Zhao X., Alimohammadisagvand B., Hasan A. 2012. Indirect Evaporative cooling: Past, present and future potentials. Renewable and Sustainable Energy Reviews 16: 6823-6850 
Duan Z. 2011. Investigation on a novel dew point indirect evaporative air conditioning system for buildings. $\mathrm{PhD}$ thesis, University of Nottingham

Gao J., Li A., Xu X., Gang W., Yan T. 2018. Ground heat exchangers: Applications, technology integration and potentials for zero energy buildings, Renewable Energy 128 (A): 337-349

Geetha N.B. and Velraj R. 2012. Passive cooling methods for energy efficient buildings with and without thermal energy storage. A review. Energy Education Science and Technology Part A: Energy Science and Research 29 :913-946

He Y., Yu H., Dong N., Ye H. 2016. Thermal and energy performance assessment of extensive green roof in summer: A case study of a lightweight building in Shanghai. Energy and Buildings 127: 762-773

Henning H.M. 2007. Solar assisted air conditioning of buildings - an overview. Applied Thermal Engineering 27: 1734-1749

Ibrahim E., Shao L., Riffat S.B. 2003. Performance of porous ceramic evaporators for building cooling application. Energy and Buildings 35: 941-949

International Energy Agency, 1997, Energy Conservation in Buildings, and Community Systems Programs. Selection guidance for low energy cooling technologies, Annex 28 Low Energy Cooling.

International Energy Agency. 2013. International Energy Outlook 2013 http://www.eia.gov/forecasts/ieo/pdf/0484\%282013\%29.pdf

IPCC (Intergovernmental Panel on Climate Change), 2001, Third Assessment Report: Climate Change 2001

Isaac M., Van Vuuren D.P. 2009. Global residential sector energy demand for heating and air conditioning in the context of climate change. Energy Policy 37: 507-521

Khabbaz M., Benhamou B., Limam K., Hollmuller P., Hamdi H., Bennouna A. 2016. Experimental and numerical study of an earth-to-air heat exchanger for air cooling in a residential building in hot semi-arid climate, Energy and Buildings 125 (1) : 109-121

Leroux G., Stephan L., Le Pierrès N., Wurtz E., Mendes N. 2015. An innovative cooling system based on evaporation from a porous tank. Proceedings $14^{\text {th }}$ international conference of IBPSA 2015 (Hyderabad) p 2453

Leroux G. 2016. Etude d'un système innovant de rafraîchissement à basse consommation pour le bâtiment, $\mathrm{PhD}$ thesis Grenoble University, october 2016

Leroux G., Mendes N., Stephan L., Le Pierrès N., Wurtz E. 2018. Innovative low-energy evaporation cooling system for buildings: study of the porous evaporator wall. Journal of Building Performance Simulation, Published online: 5 September 2018.

Liu Z., Li W., Chen Y., Luo Y., Zhang L. 2019. Review of energy conservation technologies for fresh air supply in zero energy buildings, Applied Thermal Engineering 148 (5): 544-556 
Lu X. Xu P. Wang H. Yang T. Hou J. 2016. Cooling potential and applications prospects of passive cooling in buildings: The current state-of-the-art. Renewable and Sustainable Energy Reviews 65: 1076-1097

Mihalakakou G. Santamouris M. Asimakopoulos D. 1994. On the cooling potential of earth to air heat exchangers. Energy Conversion and Management 35: 1926-1938

Oropeza-Perez I. and Østergaard P.A. 2018. Active and passive cooling methods for dwellings: A review, Renewable and Sustainable Energy Reviews 82 (1): 531-544

Santamouris M. and Kolokotsa D. 2013. Passive cooling dissipation techniques for buildings and other structures: The state of art. Energy and Buildings 57: 74-94

Shen C. and Li X. 2016. Dynamic thermal performance of pipe-embedded building envelope utilizing evaporative cooling water in the cooling season. Applied Thermal Engineering 106: 1103-1113

Singh R., Sawhney R.L., Lazarus I.J., Kishore V.V.N. 2018. Recent advancements in earth air tunnel heat exchanger (EATHE) system for indoor thermal comfort application: A review. Renewable and Sustainable Energy Reviews 82 (3): 2162-2185

Soni S.K., Pandey M., Bartaria V.N. 2016. Hybrid ground coupled heat exchanger systems for space heating/cooling applications: A review. Renewable and Sustainable Energy Reviews 60: 724-738

Spanakia A., Tsoutsosb T., Kolokotsab D. 2011. On the selection and design of the proper roof pond variant for passive cooling purposes. Renewable and Sustainable Reviews 15 : 3523-3533

Stephan L. 2012. Système de refroidissement amélioré pour bâtiments à basse consommation d'énergie. Institut national de la propriété intellectuelle, 2985806: 1250390

Stylianou I.I., Florides G., Tassou S., Tsiolakis E.,Christodoulides P. 2017. Methodology for estimating the ground heat absorption rate of Ground Heat Exchangers, Energy 127: 258-270

Velasco Gomez E., Rey Martinez F.J., Tejero Gonzalez A. 2010. Experimental characterisation of the operation and comparative study of two semi-indirect evaporative systems. Applied Thermal Engineering 30: 1447-1454 